
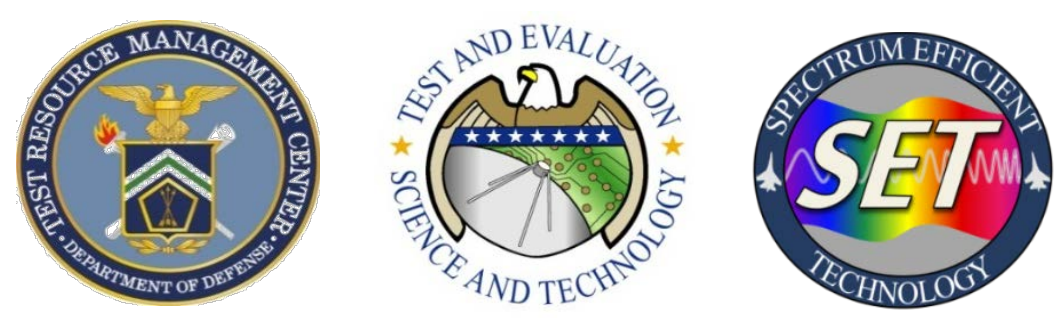

\title{
Demonstration results of the triband, multi-beam, Airborne Telemetry Phased Array (AirPA) system
}

\section{March 2015}

Tom Young

SET Executing Agent

412 TENG/ENI

(661) 277-1071

Email: tommy.young.1@us.af.mil

DISTRIBUTION STATEMENT A. Approved for public release: distribution unlimited.

Test Resource Management Center (TRMC) Test \& Evaluation/ Science \& Technology (T\&E/S\&T) Spectrum Efficient Technology (SET) 


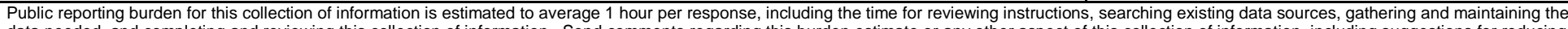

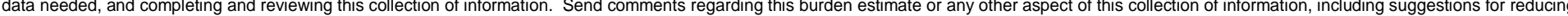

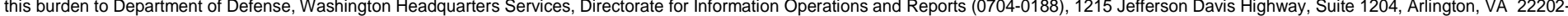

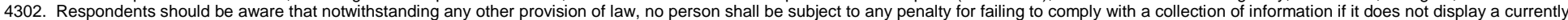
valid OMB control number. PLEASE DO NOT RETURN YOUR FORM TO THE ABOVE ADDRESS.

\begin{tabular}{l|l} 
1. REPORT DATE $(D D-M M-Y Y Y Y)$ & 2. REPORT TYPE
\end{tabular}

20-04-2015 $\quad$ Technical Paper

4. TITLE AND SUBTITLE

Demonstration results of the triband, multi-beam, Airborne Telemetry Phased Array (AirPA) system

6. AUTHOR(S)

Michael T. Pace, Jerret Eastburg, Janna Mitchke

3. DATES COVERED (From - To)

9/11 -- 11/14

5a. CONTRACT NUMBER:

W900KK-11-C-0030

5b. GRANT NUMBER: N/A

5c. PROGRAM ELEMENT NUMBER

5d. PROJECT NUMBER

5e. TASK NUMBER

5f. WORK UNIT NUMBER

7. PERFORMING ORGANIZATION NAME(S) AND ADDRESS(ES)

RAYTHEON Company

RF Systems and Engineering Department

8. PERFORMING ORGANIZATION REPORT NUMBER

1300 Eubank Blvd SE

412TW-PA-15116

Albuquerque NM 87123-3336

9. SPONSORING I MONITORING AGENCY NAME(S) AND ADDRESS(ES)

Test Resource Management Center

Test and Evaluation/ Science and Technology

4800 Mark Center Drive, Suite 07J22, Alexandria, VA 22350

$\mathrm{N} / \mathrm{A}$

12. DISTRIBUTION I AVAILABILITY STATEMENT

Approved for public release A: distribution is unlimited.

\section{SUPPLEMENTARY NOTES}

CA: Air Force Flight Test Center Edwards AFB CA CC: 012100

\section{ABSTRACT}

As the telemetry community transitions into C-band with an ever increasing number of simultaneous targets on the range, there is a strong desire to track multiple targets from a single asset in all three telemetry bands. Through the AirPA program, Raytheon has developed a triband, multi-target telemetry reception system which is capable of tracking targets in azimuth and elevation. During the AirPA Phase 3 test event in September 2014, the element level digital beamforming phased array was successfully demonstrated at Edwards Air Force Base in L-band, S-band, and C-band at a technology readiness level of 6. The system tracked both ground and air mobile transmitters using ARTM Tier 0 and Tier 1 modulation techniques. A total of twelve simultaneous tracking beams were demonstrated across all three telemetry bands. This paper will discuss the results of the demonstration, as well as several possible paths forward for the technology.

\section{SUBJECT TERMS}

AirPA, Airborne Telemetry Phased Array, antenna, digital beam-forming, beamforming, DBF, L-band, S-band, C-band, CTEIP, NAVAIR

\begin{tabular}{|c|c|c|c|c|c|}
\hline \multicolumn{3}{|c|}{$\begin{array}{l}\text { 16. SECURITY CLASSIFICATION OF: } \\
\text { Unclassified }\end{array}$} & \multirow{2}{*}{$\begin{array}{c}\text { 17. LIMITATION } \\
\text { OF ABSTRACT } \\
\text { None }\end{array}$} & \multirow{2}{*}{$\begin{array}{c}\text { 18. NUMBER } \\
\text { OF PAGES } \\
12\end{array}$} & $\begin{array}{c}\text { 19a. NAME OF RESPONSIBLE PERSON } \\
412 \text { TENG/EN (Tech Pubs) }\end{array}$ \\
\hline $\begin{array}{l}\text { a. REPORT } \\
\text { Unclassified }\end{array}$ & $\begin{array}{l}\text { b. ABSTRACT } \\
\text { Unclassified }\end{array}$ & $\begin{array}{l}\text { c. THIS PAGE } \\
\text { Unclassified }\end{array}$ & & & $\begin{array}{l}\text { 19b. TELEPHONE NUMBER (include area } \\
\text { code) } \\
661-277-8615\end{array}$ \\
\hline
\end{tabular}




\title{
Demonstration results of the triband, multi-beam, Airborne Telemetry Phased Array (AirPA) system
}

\author{
Michael T. Pace \\ Jerret Eastburg \\ Janna Mitchke \\ RF Systems and Engineering Department \\ Raytheon Ktech, Albuquerque, NM 87123 USA \\ Submitted to: \\ International Telemetering Conference 2015
}

\begin{abstract}
As the telemetry community transitions into C-band with an ever increasing number of simultaneous targets on the range, there is a strong desire to track multiple targets from a single asset in all three telemetry bands. Through the AirPA program, Raytheon has developed a triband, multi-target telemetry reception system which is capable of tracking targets in azimuth and elevation. During the AirPA Phase 3 test event in September 2014, the element level digital beamforming phased array was successfully demonstrated at Edwards Air Force Base in Lband, S-band, and C-band at a technology readiness level of 6 . The system tracked both ground and air mobile transmitters using ARTM Tier 0 and Tier 1 modulation techniques. A total of twelve simultaneous tracking beams were demonstrated across all three telemetry bands. This paper will discuss the results of the demonstration, as well as several possible paths forward for the technology.
\end{abstract}

\section{Introduction}

The AirPA system is an element level digital beamforming (DBF) phased array which is capable of receiving telemetry streams within the three principle telemetry bands $(\mathrm{L}, \mathrm{S}$, and $\mathrm{C})$. Supporting telemetry streams up to 30 MPBS with ARTM Tier 0 and Tier I modulation types, the AirPA Phase 3 DBF is designed to efficiently use the available telemetry spectrum. The system is capable of providing up to twelve beams in L-band, S-band, or C-band with four $70 \mathrm{MHz}$ Intermediate Frequency (IF) outputs. A block diagram of the system and a picture of the final hardware can be found below in Figure 1. 


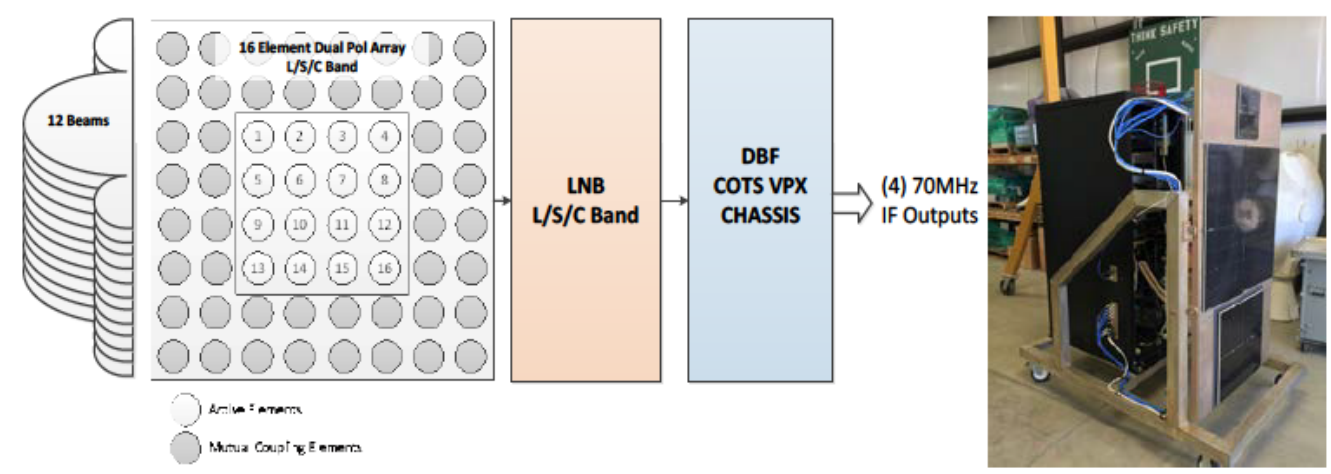

Figure 1: AirPA Phase 3 Block Diagram and Integrated System Pallet (ISP)

The AirPA system features a high efficiency microstrip antenna array, a low noise block downconverter, an element level digital beam-former, and a multi-channel IF output Digital to Analog Converter (DAC).

\subsection{Motivation}

As the available telemetry spectrum diminishes due to increase operations tempo and spectrum sell off, the test and evaluation community requires telemetry assets which are capable of tracking multiple targets across all three principle telemetry bands. To accurately support multi-target tracking, the telemetry system must have a large, grating lobe free, scan volume which does not suffer from significant scan

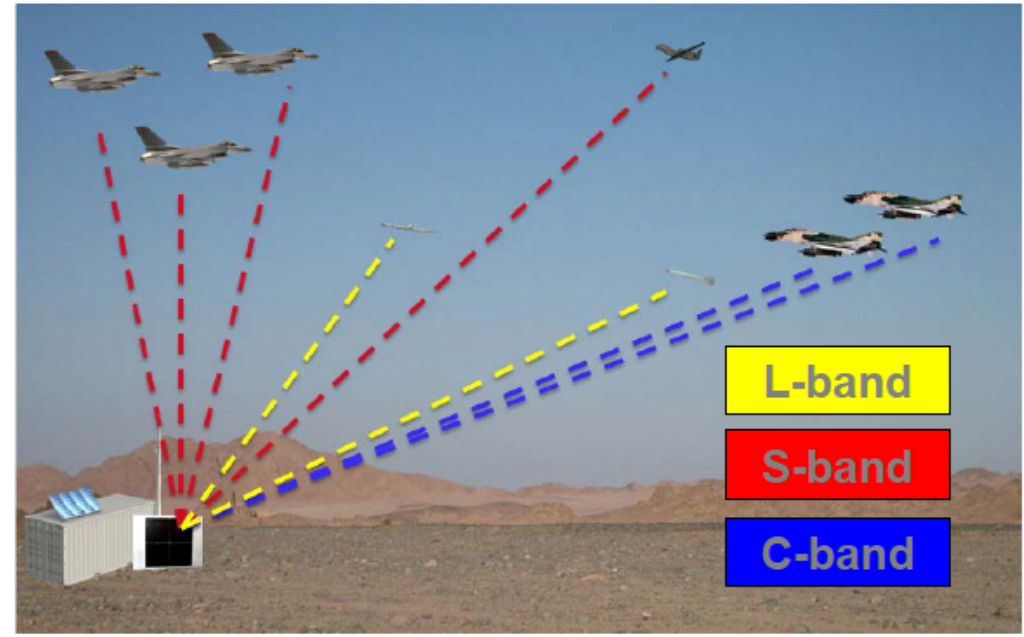

Figure 2: Multi-target mission and test scenario. loss when steered off boresite. The AirPA system directly addresses these needs by providing element level digital beamforming across L, S, and C band as seen in Figure 2 .

\section{EAFB Phase 3 Demo}

The primary goal of the Phase 3 demo was to demonstrate multi-beam operation of the system in a mission representative environment. A measure of the system's ability to process complex 
telemetry waveforms while tracking moving objects was also a prime objective of the Phase 3 demo. The results from each test event are summarized below in sections 5.1 and 5.2.

The Phase 3 demonstration was conducted on September $23^{\text {rd }}$ and $24^{\text {th }}, 2014$ at Edwards Air Force Base in California.

\subsection{Setup}

The system was configured to track a 1 MBPS SOQPSK telemetry stream from both a ground site and a C12 aircraft with multiple beams. The $70 \mathrm{MHz}$ IF output of the system was connected to demodulators, bit synchronizers, and recorders to validate the quality of the received data as shown in Figure 3.

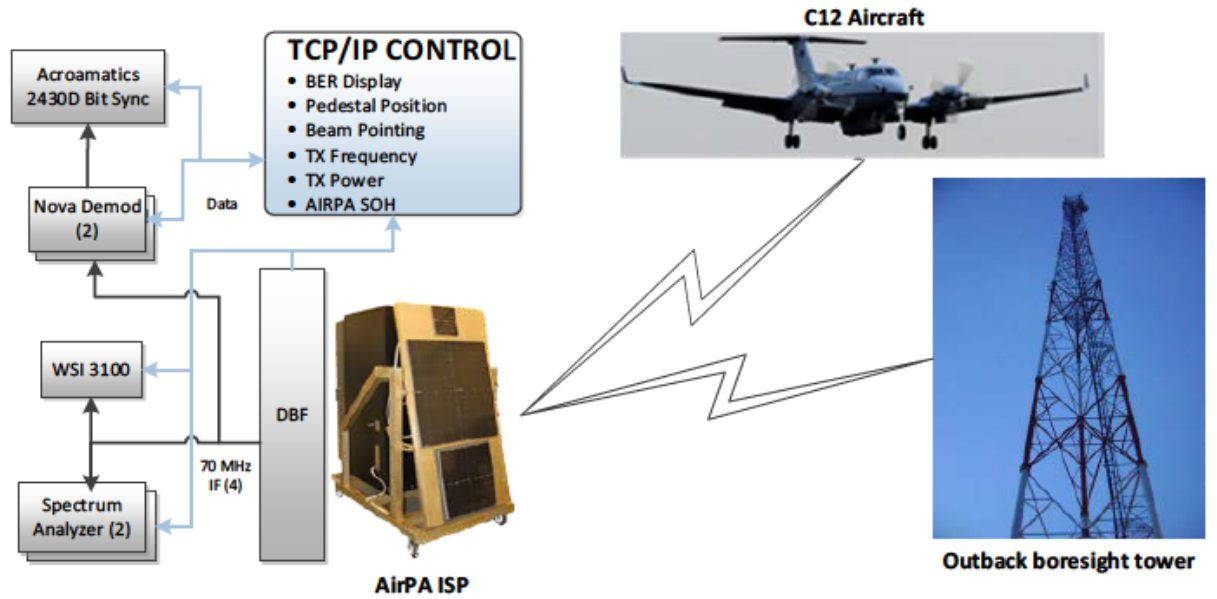

Figure 3: Test configuration for Demo

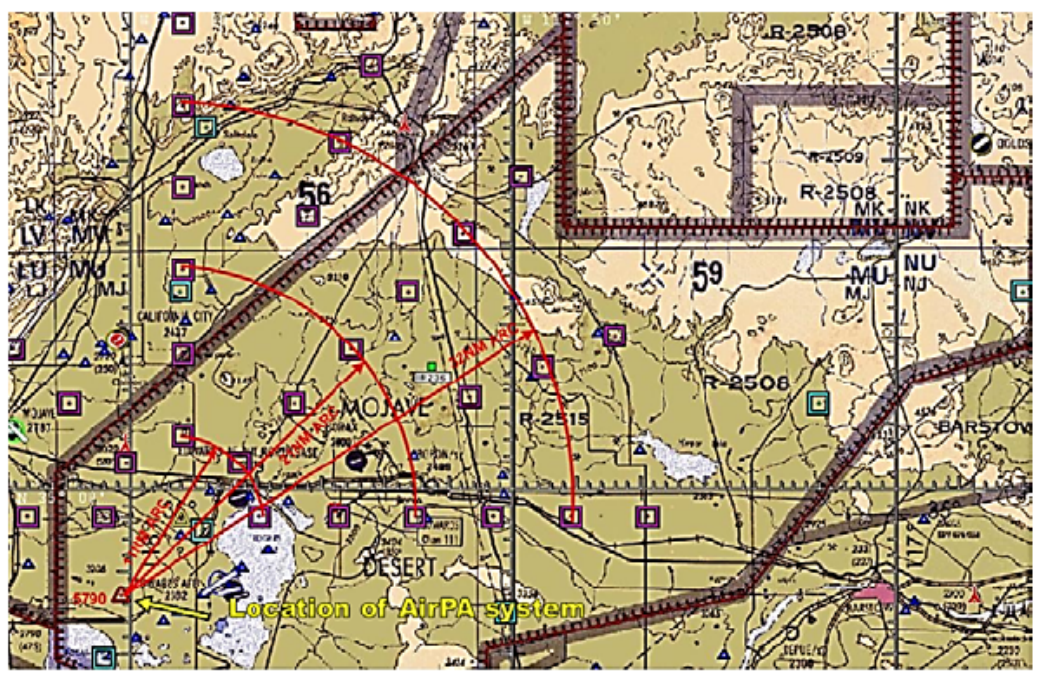

Figure 4: Phase 3 demo flight plan

Copyright (ङ 2015 Raytheon Company. All rights reserved. 
The $\mathrm{C} 12$ aircraft was equipped with a tri-band transmitter which allowed the aircraft to transmit in L-band, S-band, or C-band while maneuvering on the range per the fight plan shown above in Figure 4. The system configuration including frequencies, bandwidths, number of beams, and modulation types used for the demo can be found below in Table 1.

\begin{tabular}{|c|c|c|c|c|c|}
\hline Band & Asset & Frequency & $\begin{array}{c}\text { IF } \\
\text { Bandwidth }\end{array}$ & $\begin{array}{l}\text { Modulation } \\
\text { Type / Rate }\end{array}$ & $\begin{array}{c}\text { Number } \\
\text { of } \\
\text { beams }\end{array}$ \\
\hline \multirow[t]{2}{*}{ S-band } & Outback tower & $2201.5 \mathrm{MHz}$ & \multirow[t]{6}{*}{$3.75 \mathrm{MHz}$} & \multirow{6}{*}{$\begin{array}{c}\text { SOQPSK } \\
1 \text { MBPS }\end{array}$} & 2 \\
\hline & C12 aircraft & $2205.5 \mathrm{MHz}$ & & & 2 \\
\hline \multirow[t]{2}{*}{ L-band } & Outback tower & $1436.5 \mathrm{MHz}$ & & & $\frac{6}{6}$ \\
\hline & C12 aircraft & $1467.5 \mathrm{MHz}$ & & & 6 \\
\hline \multirow[t]{3}{*}{ C-band } & Outback tower & $5105.5 \mathrm{MHz}$ & & & 2 \\
\hline & C12 aircraft & $5115.5 \mathrm{MHz}$ & & & 2 \\
\hline & High Rate TM & $5115.5 \mathrm{MHz}$ & $30 \mathrm{MHz}$ & $\begin{array}{l}\text { SOQPSK } \\
12 \text { MBPS }\end{array}$ & 1 \\
\hline
\end{tabular}

Table 1: System Configuration for demo

\subsection{Results}

The system was configured for S-band operation to support the first flight test, Flight 170 , on Tuesday the $23^{\text {rd }}$ of September 2014. Prior to the C12 taxiing, the system was configured to slave beams 1 and 2 to the outback tower and begin collecting BER data on the 1 MBPS SOQPSK telemetry stream. The system was also commanded to acquire on Beams 6 and 7 at an initial acquisition point in the direction of the airfield. Prior to takeoff, the telemetry transmitter on the $\mathrm{C} 12$ was turned on and the AirPA system quickly acquired and initiated tracking on both beams 6 and 7 . Initially, the system was not detecting a PN11 pattern on the $C 12$ link. After further investigation, it was determined that the $\mathrm{C} 12$ was still outputting TSPI data not a PN11 pattern as expected. Once the data source was corrected, the AirPA system locked on the PN11 sequence and BER statistics were collected. During flight, the aircraft

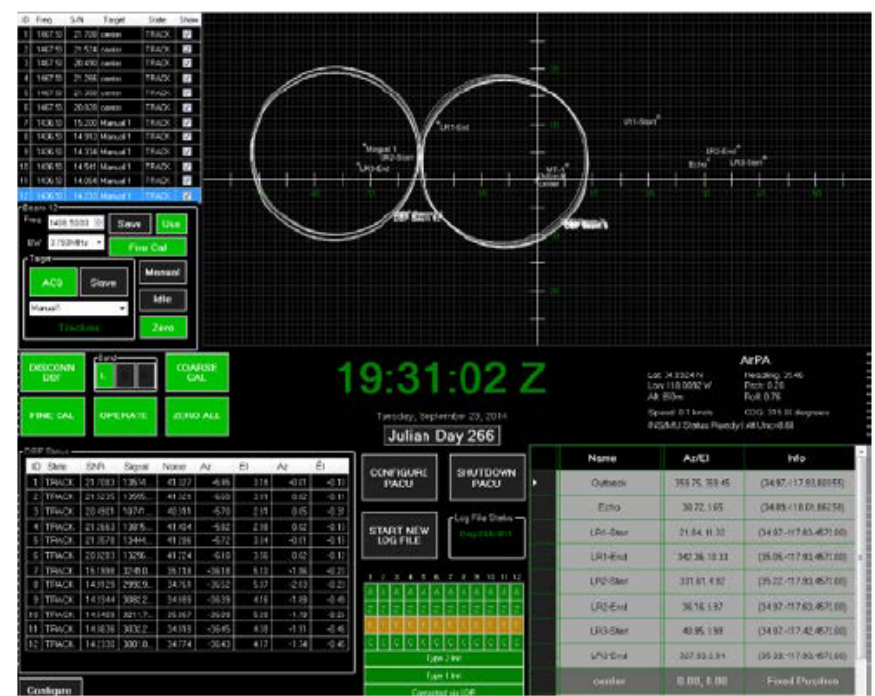

Figure 5: The user interface showing tracking solutions for multiple beams. recorded Time Space and Position Information (TSPI) to hold as truth data. The recorded truth data allowed Raytheon to analyze how well the system was tracking a dynamic source.

Copyright $\odot 2015$ Raytheon Company. All rights reserved. 
Additionally the operator has access to a user interface which reports the pointing angle and tracking solutions for each beam along with critical mission parameters including frequency, SNR, and angular velocity. Figure 5 below shows the user interface that was captured during the EAFB demonstration. The interface shows 12 beams collectively tracking two targets. The recorded LAT/LONG TSPI data for flight 170 can be found below in Figure 6, while the slant range to target and SNR can be found in Figure 7.

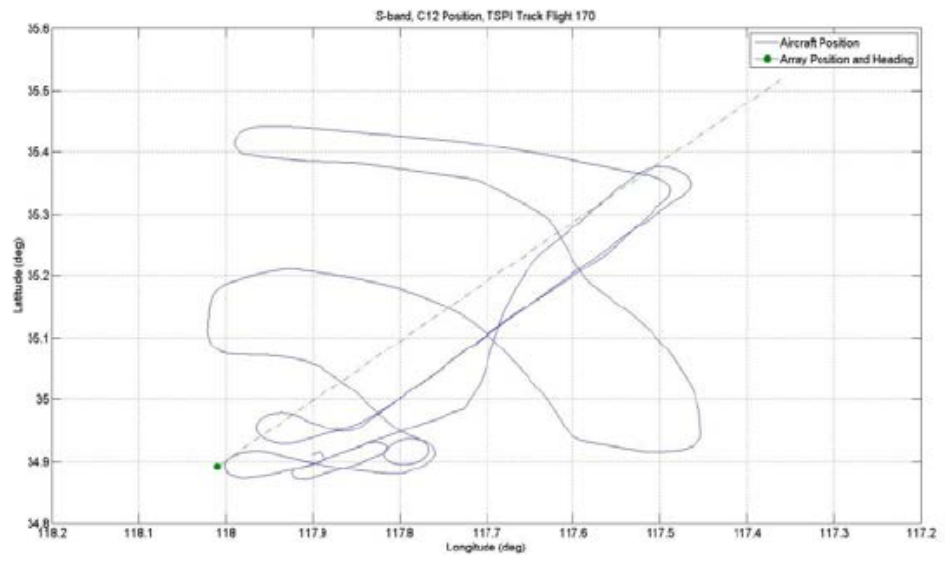

Comment [JE1]: Can we add a picture of KAOS in this document showing the number of beams? This might help for marketing and for anyone in he room to understand what the operator is seeing.

Figure 6: S-band, Flight 170 TSPI Data

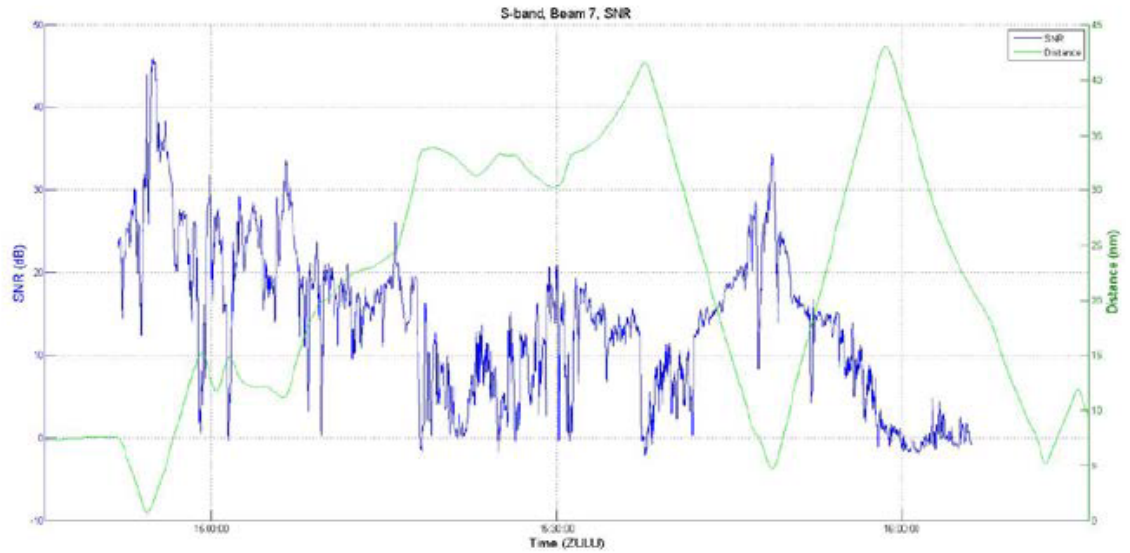

Figure 7: S-band C12 Distance vs. SNR

Over the course of the flight test, the system maintained track on both the Outback tower and the $\mathrm{C} 12$ aircraft as can be seen in Figures 8 . The accumulated BER for both the Outback tower and the $\mathrm{C} 12$ are shown in Figure 9 


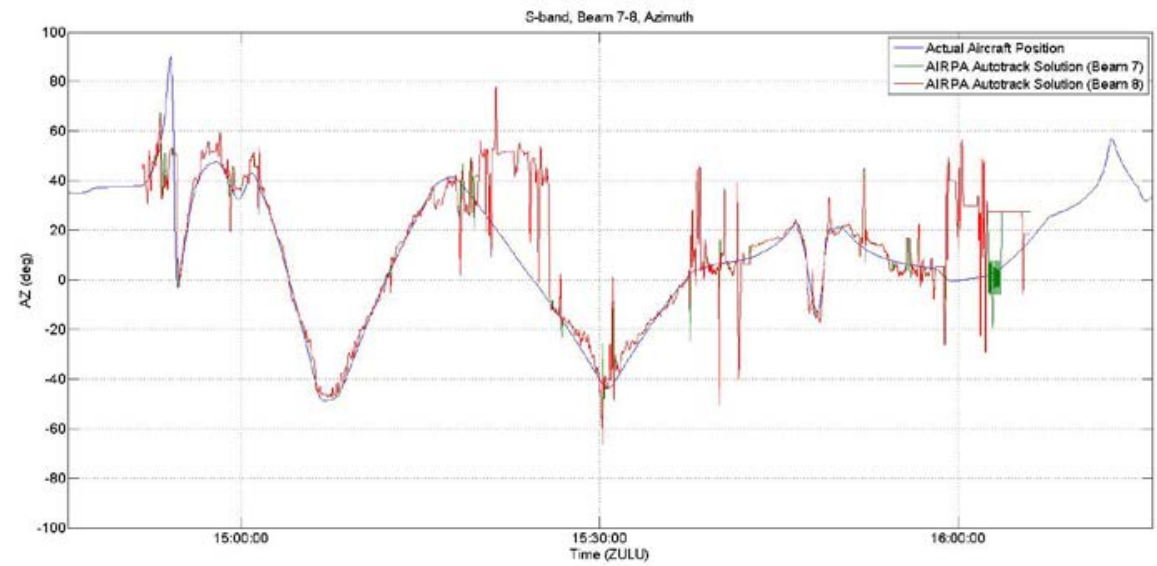

Figure 8: S-band C12 Actual Azimuth vs. Autotrack Solution

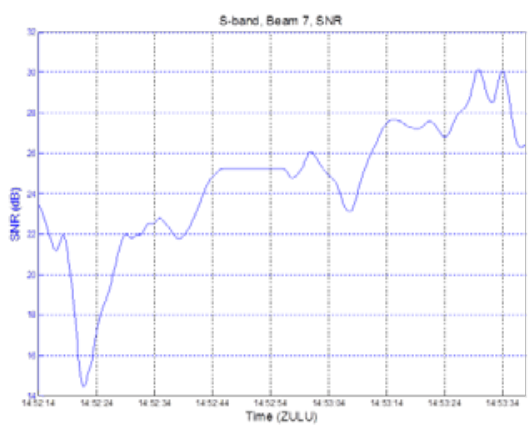

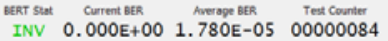

S-band, $\mathbf{C 1 2}$

1.78 E-5 Data for 84 Seconds with average SNR of $25.2 \mathrm{~dB}$

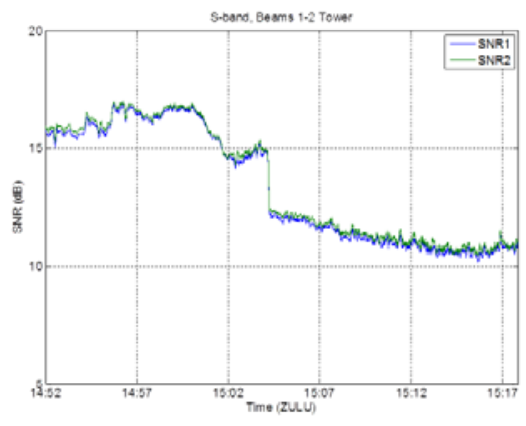

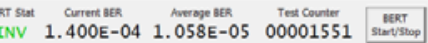
S-band, OUTBACK

1.05 E-5 Data for 1551 Seconds with an average SNR of $13 \mathrm{~dB}$

Figure 9: S-band, C12 and Outback BER

After the flight test completed, the AirPA system was reconfigured to support the L-band flight test, Flight 171. At the request of the program office, the DBF was configured to track on all twelve beams. Prior to taxi, Beams 1 through 6 were slaved to the Outback boresight tower and BER statics were collected. Similar to S-band, as soon as the C12 transmitter was turned on, the system initiated track on all six Beams 7 through 12. The C12 LAT/LONG TSPI data from Flight 171 can be found below in Figure 10, while the slant range to target and SNR can be found in Figure 11. 


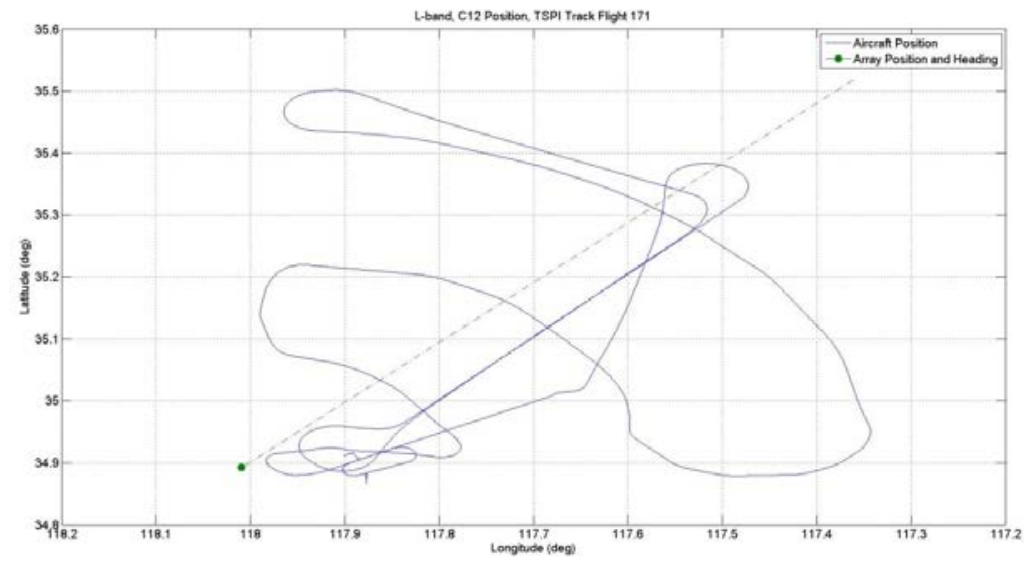

Figure 10: L-band, C12 TSPI Data

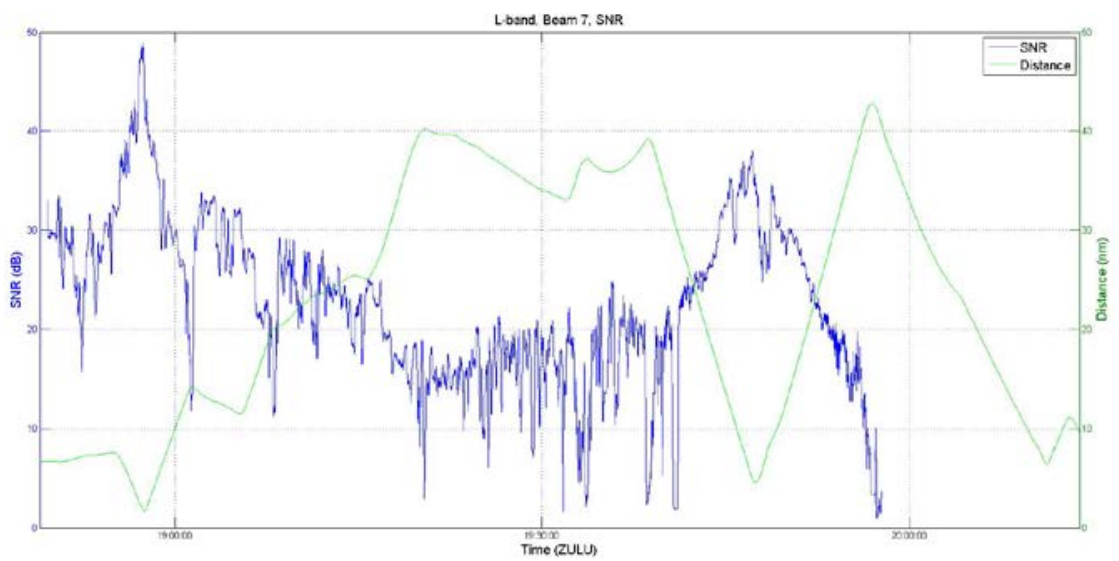

Figure 11: L-band C12 Distance vs. SNR

Throughout the flight test, the system was capable of maintaining track as can be seen in Figure 12. The accumulated BER for both the Outback tower and the C12 is in Figure 13. 


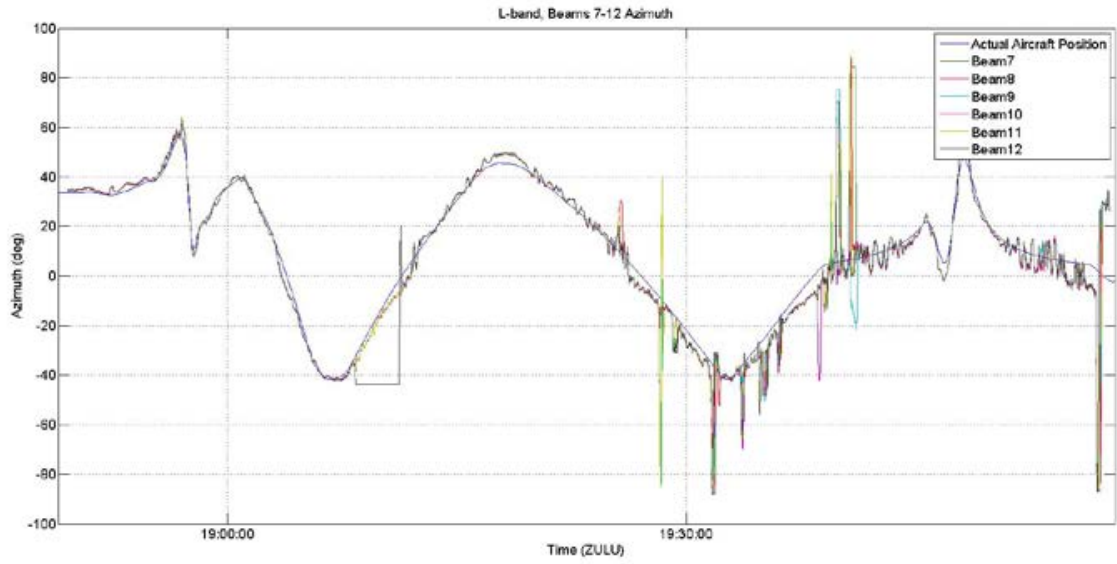

Figure 12: L-band C12 Actual Azimuth vs. Autotrack Solution
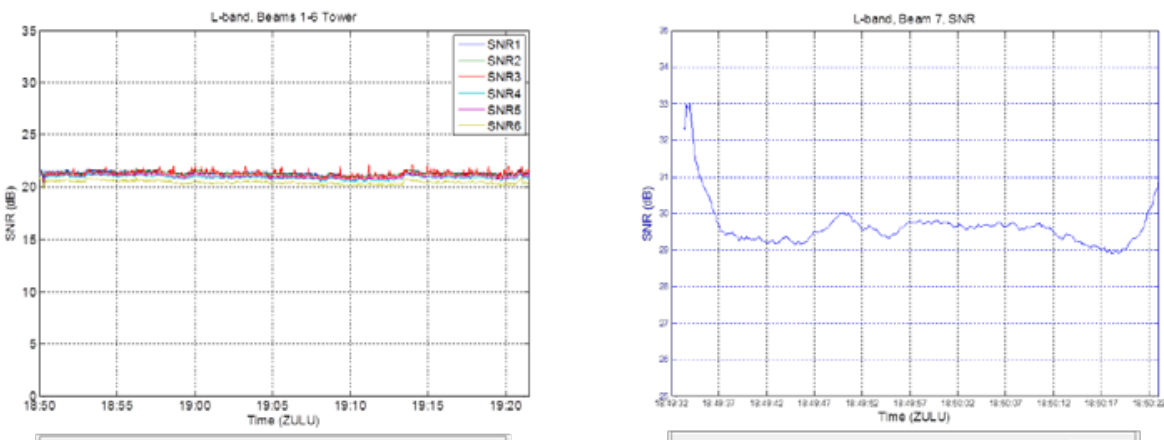

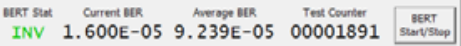

L-band, OUTBACK

9.24 E-5 Data for 1891 Seconds with

an average SNR of $22 \mathrm{~dB}$

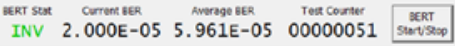

$$
\begin{aligned}
& \text { L-band, C12 }
\end{aligned}
$$

Figure 13: L-band, C12 and Outback BER

The following day, September $24^{\text {th }}$, the system was configured for C-band operations and beams 7 and 8 were slaved to the Outback tower while beams 1 and 2 were set to acquire the C12 telemetry streams. After the C12 was airborne, the system acquired on beams 1 and 2 with a notable lower observed signal to noise ratio compared to L-band. This was expected due to the increase in freespace loss at higher frequencies without a corresponding increase in the electrical aperture size. The system maintained track on the $\mathrm{C} 12$ for approximately thirty minutes before changes in the thermal environment required a quick re-calibration of the DBF. After the DBF was re-calibrated, it resumed track on both the C12 and the Outback tower. The LAT/LONG TSPI data from Flight 172 can be seen below in Figure 14, while the slant range to target and SNR can be found in Figure 15. 


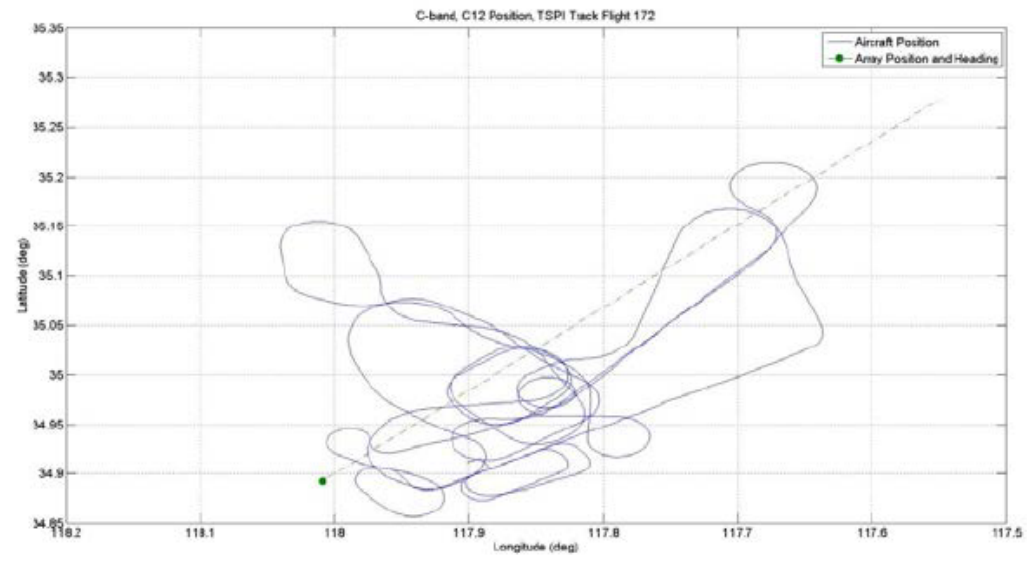

Figure 14: C-band, C12 TSPI Data

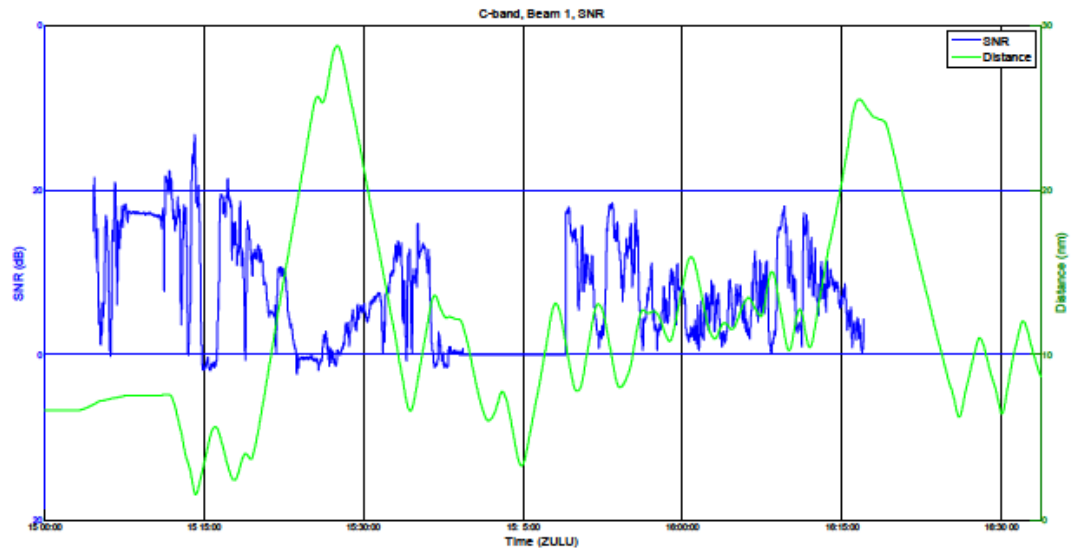

Figure 15: C-band C12 Distance vs. SNR

The tracking performance of the C-band array can be found below in Figure 16 . The accumulated BER for both the Outback tower and the C12 is shown in Figure 17 


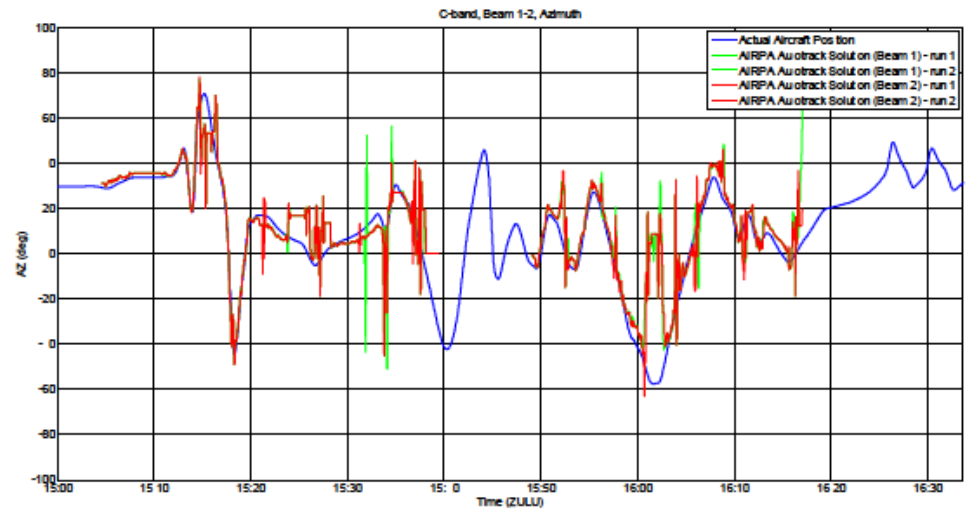

Figure 16: C-band C12 Actual Azimuth vs. Autotrack Solution
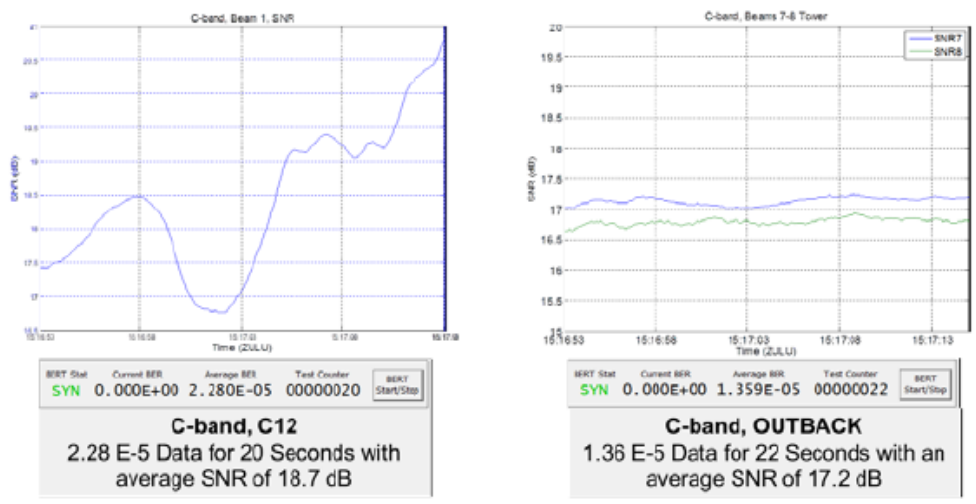

Figure 17: C-band, C12 and Outback Tower BER

\section{Conclusion}

Raytheon successfully demonstrated a tri-band multi-beam digital beamforming phased array system in a representative mission environment. The system is capable of tracking mobile aircraft and fixed sites while processing complex modulation schemes at expected BER levels with up to twelve active beams. While the system is capable of passing high rate data up to 30 MBPS, spectrum allocations limited the over the air testing to 12MBPS. Raytheon is continuing to develop this technology through internally funded development and will be expanding the capability to meet ground, air, and sea based range architecture in the near future.

\section{Acknowledgements}

The Airborne Telemetry Phased Array (AirPA) program was conducted under the U.S. Army Program Executive Office (PEO) for the Simulation Training and Instrumentation (STRI) Acquisition Center in support of the Test \& Evaluation/Science \& Technology Spectrum Efficient Technology (T\&E S\&T SET). The program greatly benefited from contributions from telemetry range subject matter experts from NAVAIR stationed at Pt. Mugu Naval Air Station. 